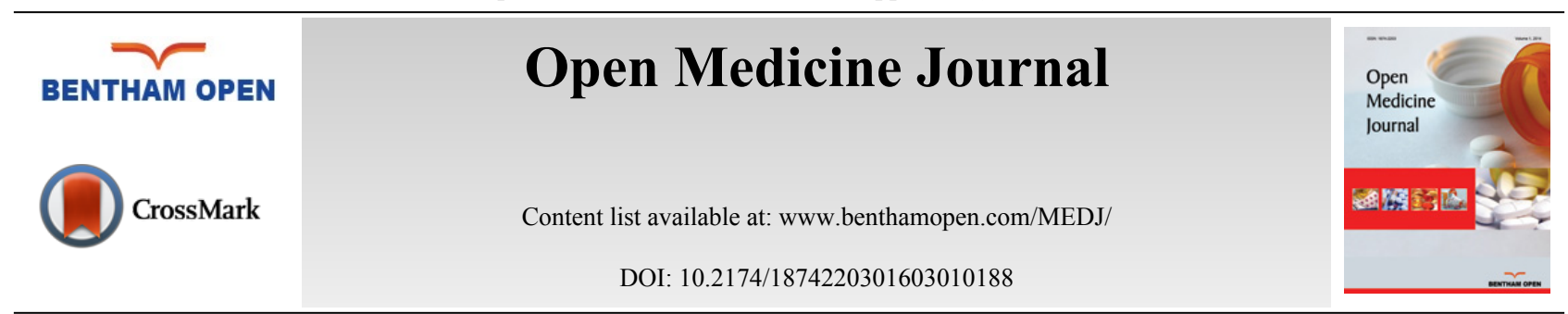

REVIEW ARTICLE

\title{
Elder Abuse in America
}

\author{
Sabrina Pickens ${ }^{*}$ and Carmel B. Dyer \\ University of Texas health Science Center-Houston School of Nursing 6901 Bertner Ave Houston, TX, 77030, USA
}

Received: September 17, 2015

Revised: October 7, 2015

Accepted: October 27, 2015

\begin{abstract}
Elder abuse is a serious social and public health issue with estimates of approximately five and a half million annual reports in the U.S. Identifying and treating abused elders is difficult due to unstandardized protocols and identification guidelines as well as a lack of public awareness to the problem. An interdisciplinary approach in collaboration with Adult Protective Services investigation is paramount to the assessment and care for mistreated elders. Educating healthcare professionals, other professions, and the lay public through social media, local news, and community education can increase awareness to this often overlooked problem.
\end{abstract}

Keywords: Abandonment, Abuse, Elder abuse, Neglect, Older adults.

\section{BACKGROUND}

Abuse in older adults is considered any act of violence or withdrawal of the necessary care to sustain life against one's consent. There are several forms of abuse that include physical abuse, caregiver neglect, psychological or emotional abuse, abandonment, self-neglect, sexual abuse and financial exploitation. Unfortunately elder abuse is a highly under recognized problem despite being a major social and public health concern [1 - 3]. Lack of standardized protocols and identification guidelines, primarily a direct result of inadequate funding, render recognizing and reporting elder abuse difficult. Prevalence and incidence rates differ across the United States (U.S.) based on varying definitions of elder abuse and who is legally responsible to report it. Despite APS agencies' availability in all fifty states, a vast majority of cases go undetected and untreated [4]. Lack of public awareness further adds to underreporting.

Experts believe that elder abuse will undoubtedly increase with the burgeoning growth of the older adult population. In 2010, approximately 40 million adults aged 65 and older resided in the United States. This same group of older Americans is the fastest growing segment of the U.S. population. By the year 2030, older adults are projected to account for $20 \%$ of the U.S. population growing from 35 million in 2000 to 72 million in 2030 due to the aging of the baby boomers [5]. With insufficient numbers of trained geriatric health care professionals, all health care professionals, other professionals and the lay public need to become aware of the signs and symptoms of elder abuse, especially elder selfneglect - the most common form, and gain better awareness of the intervention strategies [6].

\section{PREVALENCE RATES}

According to the National Center on Elder Abuse, the true number of mistreated elders is unclear due to the lack of official national statistics [7]. However, approximately five and a half million adults aged 65 years and older experienced abuse, neglect or exploitation in America [8]. More alarming, is the estimate that for every one incident reported to authorities, 4 other cases go unreported [7]. In a recent nationally randomized sample of adults 60 years and older, researchers estimated prevalence rates of approximately $11 \%$ for all forms of elder abuse utilizing a computerassisted telephone interview [9]. This study suggests a lack of precise abuse rates exist due to a lack of uniform

\footnotetext{
* Address correspondence to this author at the University of Texas health Science Center-Houston, School of Nursing, 6901 Bertner Ave, Houston, TX, 77030, USA; Tel: +713/500.2141; Fax: +713-500-2073; E-mail: Sabrina.l.pickens@uth.tmc.edu.
} 
reporting systems and a lack of comprehensive data collection across the U.S.

\section{INCIDENCE RATES}

Similar to prevalence statistics, incidence rates vary across sources. For example, in 1996 the national incidence rate for elder abuse, excluding self-neglect, was approximately 450,000 in adults 60 years of age and older. In 1999 , approximately 190,000 reports of elder abuse in the domestic setting occurred in 17 U.S. states. In a 2000 survey of domestic elder abuse, approximately 470,000 incidents occurred in 50 states partaking in the survey [10]. Another study found that 1 in every 10 older adults experienced some form of abuse with the exception of financial exploitation [11]. These figures exclude elder abuse occurring in long term care facilities.

\section{CONSEQUENCES OF ELDER ABUSE}

States spent approximately 8.5 million dollars on victims of elder abuse, a $20 \%$ increase from 2000 due to the growing number of mistreatment reports [12]. Unfortunately, older adults who suffer from abuse have at least two and half times the mortality rate than adults who have never been reported to APS [13]. When excluding all other forms of abuse, individuals who self-neglect are five times more likely to die within one year of being reported to APS compared to individual's not experiencing abuse [14]. Furthermore, many suspicious deaths related to elder abuse are often missed by medical examiners due to the lack of research and available evidence to determine if deaths are related to elder abuse or are a consequence of advanced age or disease [15].

Prior to their death, mistreated vulnerable adults may live in fear after suffering physical and/or psychological abuse. If these adults experience caregiver neglect, they may present to medical professionals with similar features of self-neglect such as multiple untreated medical conditions, excessive or lack of medications, cognitive impairment, dehydration, malnutrition, and financial exploitation.

\section{TYPES OF ELDER ABUSE}

The National Center on Elder Abuse (NCEA) and Administration of Aging provides definitions for each type of abuse and is displayed in Table $\mathbf{1}[16,17]$. Of all the types of abuse, self-neglect is the most common type of elder mistreatment reported to Adult Protective Services (APS), state agencies in charge of investigating adult abuse, neglect and exploitation in the U.S. According to the National Elder Abuse Incidence Study, approximately $18.3 \%$ of selfneglect in persons 60 years of age and older were reported in a sample of 20 counties in 15 American states [7]. Even though self-neglect is the most common report received by APS in the U.S., true incidence and prevalence rates for selfneglect are unknown since only 37 states recognize self-neglect as a form of elder abuse [2, 7, 12, 18].

Table 1. Types of elder abuse.

\begin{tabular}{|l|l|}
\hline Type of Elder Abuse & Definition \\
\hline Self-Neglect & $\begin{array}{l}\text { The behavior of an elderly person that threatens his/her own health or safety which excludes situation in which a } \\
\text { competent older person, who understands the consequences of his/her decisions, makes a conscious and voluntary } \\
\text { decision to engage in acts that threaten his/her health or safety as a matter of personal choice }\end{array}$ \\
\hline Physical Abuse & The use of physical force that may result in bodily injury, physical pain, or impairment \\
\hline Sexual Abuse & $\begin{array}{l}\text { Non-consensual sexual contact of any kind with an elderly person. Sexual contact with any person incapable of } \\
\text { giving consent is also considered sexual abuse }\end{array}$ \\
\hline $\begin{array}{l}\text { Emotional or Psychological } \\
\text { Abuse }\end{array}$ & The infliction of anguish, pain, or distress through verbal or nonverbal acts \\
\hline Neglect & Refusal or failure to fulfill any part of a person's obligations or duties to an elder \\
\hline Abandonment & $\begin{array}{l}\text { Desertion of an elderly person by an individual who has assumed responsibility for providing care for an elder, } \\
\text { or by a person with physical custody of an elder }\end{array}$ \\
\hline Financial Exploitation & Illegal or improper use of an elder's funds, property or assets [16, 17] \\
\hline
\end{tabular}

\section{RISK FACTORS FOR ELDER ABUSE}

There are several risk factors associated with elder abuse and include increased physical dependency leading to more demand of the caregiver, inadequate social support, impaired caregivers, impaired cognition, substance abuse by either the victim or the caregiver, and untreated psychiatric disorders. Additional risk factors are being from a low socioeconomic status, age, race, functional impairments, living in isolation contributing to loneliness and low educational levels [19]. 


\section{SIGNS AND SYMPTOMS OF ELDER ABUSE}

The following signs and symptoms, if present, should direct further investigation into abuse. These criteria are provided by National Center on Elder Abuse and Administration on Aging:

- Dehydration, malnutrition, untreated or improperly attended medical conditions, and poor personal hygiene,

- Inappropriate and/or inadequate clothing, lack of the necessary medical aids (e.g., eyeglasses, hearing aids, dentures),

- Suspicious patterns of bruises, fractures, abrasions, and burn marks,

- Sudden and unexplained withdrawal from normal activities,

- Bruises near/around genitalia, new onset of vaginal and/or rectal bleeding,

- Sudden change in cognition,

- Sudden changes in finances such that the elder can no longer pay bills, purchase groceries or medications,

- Verbal assault such as threats,

- Strain in the elder's relationship with the caregiver.

In the home setting, the following signs and symptoms warrant further investigation in addition to the above criteria:

- Hazardous or unsafe living conditions/arrangements (e.g., improper wiring, no indoor plumbing, no heat, no running water, lack of utilities),

- Unsanitary or unclean living quarters (e.g., animal/insect infestation, no functioning toilet, fecal/urine smell), and

- Grossly inadequate housing or homelessness [16, 17].

\section{ELDER ABUSE ASSESSMENT}

A comprehensive geriatric assessment (CGA) is often used to assess cognitive, functional and social domains and is considered the cornerstone of geriatric medicine [20]. A battery of tests may be necessary to determine whether or not the individual has the capacity for self-care and protection. A commonly used battery of tests in addition to elicited information include the following: past medical history, social history, a thorough review of all prescription and over the counter medications, Confusion Assessment Method (screen for delirium), Mini-Mental Status Examination (screen for global cognition), Geriatric Depression Scale, CLOX Drawing Test (screen for executive impairment), Kohlman Evaluation of Living Skills (assess both basic and instrumental activities of daily living) and a detailed head to toe physical examination [21 - 25]. If caregiver neglect is suspected, the victim should be interviewed alone. A separate interview with the caregiver should follow for comparison of 'stories'. Detailed descriptions of suspicious wounds should be thoroughly documented. In cases of suspected sexual assault, using direct, closed-ended questions or use of a sexual assault forensic evaluator can assist the investigation especially if the victim has dementia, limited verbal skills, and a history of child sexual abuse and/or adult sexual assault. Collection of specimens to test for sexually transmitted diseases and DNA is warranted [26]. It's of utmost importance to use direct quotes as much as possible especially if a criminal investigation ensues. Depending on the setting, photography should be used to document injury. Elderly females should be screened for both elder abuse and domestic violence since it's not determined whether elder abuse is a new case or abuse that has continued into advanced age [27]. In cases of financial exploitation, a detailed review of bank statements and other financial investments is useful. Involving representatives from financial institutions can assist with the investigation. Caseworker with APS have the authority to request these documents. After the CGA is completed a home safety evaluation is often warranted if the assessment occurs in the victim's home. A useful tool to aid in the environmental assessment is the Environmental Cleanliness and Clutter Scale [28]. The environmental assessment includes entering each room of the home, inspecting the pantries and refrigerator, and determining whether or not utilities are working. The clinician often times discovers clutter, lack of electricity and/or water, and inadequate plumbing. The refrigerator may have rotten food or scarce nutritional items.

\section{INTERVENTION STRATEGIES}

\section{Adult Protective Services}

Adult Protective Services are state agencies whose aim is to protect vulnerable adults from abuse, neglect and exploitation. These agencies were formed based on Title XX of the Social Security Act in the mid-1970s. By the early 
1980s, every state had an agency in operation. This agency's mission, in Texas, is to protect vulnerable adults including those with disabilities from abuse, neglect, and exploitation. To prevent and halt further harm in victims of abuse, APS investigates the allegations. In addition, APS can provide or arrange for services to assist the victim [29]. Other U.S. states have a similar mission statement. If abuse is suspected, individuals can report the case to APS anonymously. Table 2 provides a list of services provided by APS caseworkers [30].

Table 2. Services provided by caseworkers for adult protective services.

- Receive reports for abuse, neglect and exploitation in vulnerable adults 18 years of age and older

- Schedules a face to face visit within 24 to 72 hours depending on the allegation and whether or not the vulnerable adult is in imminent danger

- Investigates and substantiates the reason for the referral (i.e. caregiver neglect, self-neglect, physical or psychological abuse)

- Arranges for community services on a case by case basis which includes:

1. Transportation

2. Assistive devices

3. Home clean-up and repair

4. Meals on Wheels, food stamps or other food services

5. Purchases necessary medications on a short-term basis

6. Reinstates electricity, heat, and/or water

7. Emergency housing (i.e. if the victim is to be evicted or is in danger)

8. Arranges for a medical and/or mental evaluation

- Apply for emergency removals

- Apply for temporary guardianship in emergent cases

- Testify in both criminal and civil court hearings [29].

\section{Safety Issues}

If the mistreated adult is in immediate danger, in the state of Texas, nurse practitioners, nurses, physicians and social workers, and on weekends APS workers can request an emergency protective order for removal to a safer environment such as a hospital, personal care home or nursing home until a complete plan of care is developed and implemented. If the elder has weapons in his/her home or poses a threat to self or others police officers trained in crisis intervention can aid in the investigation.

\section{The Need for an Interdisciplinary Approach}

Due to the complexity of elder abuse cases and the lack of empirically tested medical interventions, an interdisciplinary approach is warranted [8]. Members from medicine, nursing, social work, APS, law enforcement, forensic specialists and case managers should participate in frequent interdisciplinary team (IDT) meetings to discuss and implement both short and long-term plans of care keeping the least restrictive alternative philosophy as the core of decision making [31]. Essentially, it's determined whether or not victims lack the capacity for self-care and protection in their current state of living. The IDT determination of capacity directs the plan of care which can result in guardianship or relocation to a safer environment. Law enforcement and forensic specialists can aid in criminal investigations.

\section{CLINICAL CONSIDERATIONS AND OUTCOMES}

The consequences for elder abuse, in general, are often manifested as behavioral problems. These include depressed mood, suicidal ideation, anxiety, worsening cognition, physical lethargy and poor sleep hygiene. Clinical outcomes for mistreated elders are greater use of emergency departments, greater hospitalization rates, relocation to long-term care for safety purposes and higher mortality rates compared to elders not experiencing abuse [32]. The problem with selfneglecters is they often unknowingly mistreat themselves. The deplorable conditions in which these individuals reside lead to severe health consequences and also death [3]. Clinical outcomes for these vulnerable self-neglecters are similar to other forms of elder mistreatment and include initiating and maintaining ongoing medical care, relocation to longterm care, environmental reform to ensure safety and assigning a guardian in select cases.

\section{COMMUNITY AWARENESS}

In an effort to prevent future abuse among vulnerable adults, it is imperative to raise community awareness to this 
major public health concern. Using various social media networks is an ideal platform to reach a larger audience on a national level. Local news media and community presentations at various locations such as churches, wellness centers, senior day centers, and college campuses can raise local awareness on identification and reporting mechanisms to this growing, national epidemic. Finally, educating healthcare workers without geriatric training, as well as postal workers, paramedics, firefighters, pastors, and meals on wheels deliverers can also improve elder abuse awareness [6].

\section{CONCLUSION}

The consequence of elder abuse is too often death when the abuse is discovered very late (if at all) when medical interventions are of no avail. The high death rate among vulnerable adults suffering from abuse is likely the consequence of isolation and chronic, untreated or undiagnosed medical conditions. The lack of available screening tools to measure all forms of elder abuse dictates that health care professionals must use clinical skill to identify abuse early and immediately implement plans of care, both short and long-term, to protect these vulnerable elders from further deterioration. Additionally, educating other professions and lay persons on the identification of elder abuse can improve early detection. Once identified, an interdisciplinary approach is a successful intervention that can improve care and possible survival rates in vulnerable adults suffering from abuse, neglect and/or financial exploitation.

\section{CONFLICT OF INTEREST}

The authors confirm that this article content has no conflict of interest.

\section{ACKNOWLEDGEMENTS}

Declared none.

\section{REFERENCES}

[1] Jogerst GJ, Daly JM, Brinig MF, Dawson JD, Schmuch GA, Ingram JG. Domestic elder abuse and the law. Am J Public Health 2003; 93(12): 2131-6.

[http://dx.doi.org/10.2105/AJPH.93.12.2131] [PMID: 14652346]

[2] Dyer CB, Goodwin JS, Pickens-Pace S, Burnett J, Kelly PA. Self-neglect among the elderly: a model based on more than 500 patients seen by a geriatric medicine team. Am J Public Health 2007; 97(9): 1671-6. [http://dx.doi.org/10.2105/AJPH.2006.097113] [PMID: 17666694]

[3] Dyer CB, Pickens S, Burnett J. Vulnerable elders: when it is no longer safe to live alone. JAMA 2007; 298(12): 1448-50. [http://dx.doi.org/10.1001/jama.298.12.1448] [PMID: 17895463]

[4] Nation Center on Elder Abuse. Statistics/Data. 2015. Available from: http://www.ncea.aoa.gov/Library/Data/index.aspx

[5] Older Americans: Key Indicators of well-being 2012. Available from: http://www.agingstats.gov/aginstatsdotnet/main_site/default.aspx

[6] Boltz M, Buckwalter K, Cortes T, Evans L, Fulmer T. Elder justice: Preventing and intervening in elder mistreatment. Elder Justice Policy Brief, version 3.5.2105. Available from: https://hign.org/sites/hartford/files/policy/hot-topics/elder-justice-series/HIGNpolicybrief_ ElderJustice_05_31_15.pdf.

[7] National elder abuse incidence study 2015. Available from: http://www.aoa.gov/eldfam/Elder_Rights/Elder_Abuse/AbuseReport_Full.pdf.

[8] Pillemer K, Connolly MT, Breckman R, Spreng N, Lachs MS. Elder mistreatment: priorities for consideration by the white house conference on aging. Gerontologist 2015; 55(2): 320-7.

[http://dx.doi.org/10.1093/geront/gnu180] [PMID: 26035609]

[9] Acierno R, Hernandez MA, Amstadter AB, et al. Prevalence and correlates of emotional, physical, sexual, and financial abuse and potential neglect in the United States: the National Elder Mistreatment Study. Am J Public Health 2010; 100(2): $292-7$. [http://dx.doi.org/10.2105/AJPH.2009.163089] [PMID: 20019303]

[10] Elder abuse prevalence and incidence 2015. Available from: http://www.ncea.aos.gov/ncearoot/Main-Site /pdf/publication/FinalStatistics050331.pdf.

[11] Teaster PB, Dugar T, Mendiondo M, Abner EL, Cecil KA, Otto JM. The 2004 survey of adult protective services: Abuse of adults 60 years of age and older. District of Columbia: National Center on Elder Abuse 2004.

[12] Administration on Aging. The 2004 Survey of State Adult Protective Services: Abuse of Adults 60 Years of Age and Older 2004. Available from: http://www.aoa.gov/NCEAroot/Main_Site/pdf/2-14-06\%20FINAL\%2060+REPORT.pdf.

[13] Lachs MS, Williams CS, O’Brien S, Pillemer KA, Charlson ME. The mortality of elder mistreatment. JAMA 1998; 280(5): 428-32. [http://dx.doi.org/10.1001/jama.280.5.428] [PMID: 9701077]

[14] Dong X, Simon M, Mendes de Leon C, et al. Elder self-neglect and abuse and mortality risk in a community-dwelling population. JAMA 2009; 302(5): 517-26.

[http://dx.doi.org/10.1001/jama.2009.1109] [PMID: 19654386] 
[15] Dyer CB, Sanchez L, Kim L, et al. National Institute of Justice. Factors that impact the determination by medical examiners of elder mistreatment as a cause of death in older people. U.S. Department of Justice 2008.

[16] National Center on Elder Abuse. Types of Abuse. Available from: http://www.ncea.aoa.gov/ncearoot/Main_Site/FAQ /Basics/Types_Of_Abuse.aspx. 2015.

[17] Administration on Aging. Warning signs of EA. Available from: http://www.aoa.gov/AoA_programs/Elder_Rights /EA_Prevention/whatIsEA.aspx. 2015.

[18] Pavlik VN, Hyman DJ, Festa NA, Bitondo Dyer C. Quantifying the problem of abuse and neglect in adults- analysis of a statewide database. J Am Geriatr Soc 2001; 49(1): 45-8.

[http://dx.doi.org/10.1046/j.1532-5415.2001.49008.x] [PMID: 11207841]

[19] Fulmer T. Mistreatment of Older Adults. In: Durso S, Sullivan G, Eds. Geriatric review syllabus: A Core Curriculum in Geriatric Medicine. New York: American Geriatric Society 2013; pp. 104-8.

[20] Duthie EH, Kazt PR, Malone ML. The Practice of Geriatrics. $4^{\text {th }}$ ed. Pennsylvania: Saunders Elsevier 2007.

[21] Inouye SK, van Dyck CH, Alessi CA, Balkin S, Siegal AP, Horwitz RI. Clarifying confusion: the confusion assessment method. A new method for detection of delirium. Ann Intern Med 1990; 113(12): 941-8. [http://dx.doi.org/10.7326/0003-4819-113-12-941] [PMID: 2240918]

[22] Folstein MF, Folstein SE, McHugh PR. "Mini-mental state". A practical method for grading the cognitive state of patients for the clinician. J Psychiatr Res 1975; 12(3): 189-98. [http://dx.doi.org/10.1016/0022-3956(75)90026-6] [PMID: 1202204]

[23] Yesavage JA, Brink TL, Rose TL, et al. Development and validation of a geriatric depression screening scale: a preliminary report. J Psychiatr Res 1982-1983; 17(1): 37-49.

[http://dx.doi.org/10.1016/0022-3956(82)90033-4] [PMID: 7183759]

[24] Royall DR, Cordes JA, Polk M. CLOX: an executive clock drawing task. J Neurol Neurosurg Psychiatry 1998; 64(5): 588-94. [http://dx.doi.org/10.1136/jnnp.64.5.588] [PMID: 9598672]

[25] Kohlman-Thomson L. The Kohlman Evaluation of Living Skills. $3^{\text {rd }}$ ed. MD: American Occupational Therapy Association 1992.

[26] Speck PM, Hartig MT, Likes W, et al. Case series of sexual assault in older persons. Clin Geriatr Med 2014; 30(4): 779-806. [http://dx.doi.org/10.1016/j.cger.2014.08.007] [PMID: 25439642]

[27] Fulmer T, Guadagno L, Bolton MM. Elder mistreatment in women. J Obstet Gynecol Neonatal Nurs 2004; $33(5)$ : 657-63. [http://dx.doi.org/10.1177/0884217504268873] [PMID: 15495712]

[28] Halliday G, Snowdon J. The environmental cleanliness and clutter scale (eccs). Int Psychogeriatr 2009; 21(6): 1041-50. [http://dx.doi.org/10.1017/S1041610209990135] [PMID: 19589191]

[29] Bonnie RJ. In Elder Mistreatment: Abuse, Neglect, and Exploitation in an Aging America. District of Columbia: The National Academies Press 2003.

[30] Brandl B, Dyer CB, Heisler C, Otto JM, Stiegel LA, Thomas RW. The Elder Abuse Detection and Intervention: A Collaborative Approach. New York: Springer Publishing Co. 2007.

[31] Dyer CB, Gleason MS, Murphy KP, et al. Treating elder neglect: collaboration between a geriatrics assessment team and adult protective services. South Med J 1999; 92(2): 242-4. [http://dx.doi.org/10.1097/00007611-199902000-00017] [PMID: 10071677]

[32] Dong X. Elder abuse: research, practice, and health policy. The 2012 GSA Maxwell Pollack award lecture. Gerontologist 2014; 54(2): $153-62$.

[http://dx.doi.org/10.1093/geront/gnt139] [PMID: 24270215]

(C) Pickens and Dyer; Licensee Bentham Open

This is an open access article licensed under the terms of the Creative Commons Attribution-Non-Commercial 4.0 International Public License (CC BY-NC 4.0) (https://creativecommons.org/licenses/by-nc/4.0/legalcode), which permits unrestricted, non-commercial use, distribution and reproduction in any medium, provided the work is properly cited. 